\title{
RELENDO "QUARTO DE DESPEJO: DIÁRIO DE UMA FAVELADA" PELA TEORIA BAKHTINIANA
}

\author{
RE-READING "QUARTO DE DESPEJO: DIÁRIO DE UMA FAVELADA" BY \\ BAKHTINIANA THEORY
}

Daniela Rebello Pereira Sylvestre ${ }^{1}$

RESUMO: O artigo versa sobre alguns conceitos da teoria do Círculo de Bakhtin: dialogismo, o outro (alternância dos sujeitos falantes), atitude responsiva e esferas da comunicação. Desenvolveu-se por meio do diálogo entre a análise e exemplificação de trechos do livro "Quarto de despejo: diário de uma favelada" de Carolina Maria de Jesus. Como resultado nos deparamos com a força e potência comunicativa da literatura marginal da autora para pensar a atualidade dos conceitos bakhtinianos. Concluímos ressaltando o vínculo entre a língua e vida, após demonstrar as influências do contexto social, da ideologia dominante e da luta de classes em trechos do livro.

Palavras-chave: Linguagem. Literatura Marginal. Bakhtin. Carolina Maria de Jesus.

ABSTRACT: The article deals with some concepts of Bakhtin's Circle theory: dialogism, the Other (alternation of speaking subjects), responsive attitude and spheres of communication. It was developed through the dialogue between the analysis and illustration of excerpts from the book "Quarto de despejo: Diário de uma favelada" by Carolina Maria de Jesus. As a result, we are faced with the strength and communicative power of the author's marginal literature to think about the actuality of Bakhtinian concepts. We conclude by emphasizing the link between language and life, after demonstrating the influences of social context, dominant ideology and class struggle in excerpts from the book.

Keywords: Language. Marginal Literature. Bakhtin. Carolina Maria de Jesus.

\section{I- INTRODUÇÃO}

O filósofo da linguagem Mikhail Mikhailovich Bakhtin (1895-1975) foi um pensador russo, estudioso dos fenômenos linguísticos, que juntamente a outros estudiosos, como o linguista Valentin Voloshinov (1895-1936) e o teórico literário Pavel Medvedev (1891-1938), entre outros, formaram o Círculo de Bakhtin. Juntos, eles

\footnotetext{
${ }^{1}$ Professora de Língua Portuguesa. Servidora pública do RJ e do município de Magé. Pós-graduada em Leitura e Produção Textual e Neuropsicopedagogia. ID Orcid: oooo-ooo3-0521-3024.; E-mail: drebellop@gmail.com
} 
revolucionaram as teorias linguísticas do século 20 ao pensar e enxergar a linguagem como um constante processo de interação mediado pelo diálogo - e não apenas como um sistema autônomo. Os três autores russos problematizam a linguagem e revolucionaram a linguística porque a entenderam sob o viés sociológico, histórico e ideológico, onde a interação verbal ocorre numa relação dialógica, em um contexto em que todos participam em condição de igualdade.

Carolina Maria de Jesus (1914-1977) é considerada a pioneira na literatura brasileira marginal ${ }^{2}$. Era uma mulher negra, favelada, mãe solteira de três filhos e com pouco estudo. Ela sobrevivia catando papelão e ferro pelas ruas e lixões de São Paulo, quando o jornalista Audálio Dantas, em 1958, encontra-a enquanto estava na favela do Canindé, às margens do rio Tietê, em São Paulo, para uma reportagem sobre um parque infantil. Carolina tinha 43 anos e com a ajuda do jornalista viu potencial em seus escritos de diário e ajudou-a a publicá-lo; ela ficou conhecida mundialmente por "Quarto de Despejo: Diário de uma Favelada" (1960), clássico da nossa literatura.

O livro é um romance, uma coletânea de seus escritos em 20 cadernos encardidos, são textos no gênero diário pessoal em linguagem com muitos traços de oralidade e desvios gramaticais que foram preservados na edição e publicação, assim tais marcas explicitam o cotidiano da escritora, bem como singularizam ainda mais a sua obra. À medida que a escrita pretendia projetar em seus diários uma imagem de escritora culta, no entanto, sua oralidade não intencional mesclada pela busca de palavras cultas é pulsante em seu discurso, conforme será demonstrado em alguns excertos no desenvolvimento deste artigo.

Em "Estética da criação verbal", Bakhtin apresenta conceitos primordiais que necessitam ser compreendidos para a análise que faremos sobre o livro a ser analisado da autora acima citada.

O enunciado seja oral ou escrito é sempre individual em qualquer esfera da comunicação verbal, mas nem todos os gêneros do discurso são propícios à expressão da

\footnotetext{
${ }^{2}$ Surgiu em meados de 1970, tendo como principal característica a quebra de padrões literários da época. Relembrando que nesse período houve a implementação do ato institucional número 5 (AI-5) no Brasil, que repreendeu todo o tipo de liberdade de expressão. Atualmente, é também conhecida como Literatura Periférica, dando voz às pessoas que vivem à margem da sobrevivência.
} 
individualidade, os mais propícios são os literários. Os gêneros do discurso que menos favorecem a expressão da individualidade são os padronizados como relatórios e ofícios, por exemplo.

O enunciado é a unidade real de comunicação verbal e é sempre uma forma de diálogo com o Outro (s), é sempre uma atitude responsiva, nem sempre ativa, pode ser muda, como nos gêneros líricos que não suscitam uma resposta para a sua compreensão. Cabe lembrar que todo enunciado, provém de um discurso inteligível que provém de uma intenção discursiva em seu todo. E essa variedade de escopos intencionais do falante é que origina a variedade dos gêneros do discurso.

O gênero do discurso: são os tipos relativamente estáveis de enunciados elaborados por cada esfera de utilização da língua. Por isso, os gêneros são infinitos, porque são infinitas as possibilidades de variedade virtual da atividade humana. Sendo por isso mesmo, atemporais porque as atividades humanas vão se modificando e ampliando-se à medida que a própria esfera vai se desenvolvendo e complexando-se.

O autor diferencia, ainda, gêneros literários, retóricos, familiares...

Nos estudos do gênero do discurso, Bakhtin diferencia o primário $\mathrm{x}$ secundário. $\mathrm{O}$ primário engloba os enunciados simples, do dia a dia, já o secundário engloba os enunciados complexos que aparecem em circunstâncias de uma comunicação cultural, mais complexa e relativamente mais evoluída, principalmente escrita: artística, científica, sociopolítica.

\section{I.I- O que é estudar a linguagem sob um viés sociológico?}

Para Bakhtin, a língua escrita só pode ser modificada após um longo período de uso através dos gêneros do discurso, quer sejam primários ou secundários. Toda modificação na língua escrita tanto no campo fonético, lexical e/ou gramatical, perpassa pelos enunciados através do uso dos gêneros discursivos, pelo acabamento do estilo-gênero pelos falantes e ouvintes. Ou seja, por isso, as línguas se modificam ao longo da história porque os falantes estão inseridos em uma sociedade que se modifica. A língua é tão viva quanto os que dela fazem uso, não haveria porque ser imutável. Compreender a língua sob um viés sociológico, é compreender esse fenômeno, de que a 
língua é marcada pelos gêneros do discurso, que são criados e modificados pelos locutores e interlocutores de uma determinada língua, inseridos em contexto social, histórico, cultural e ideológico. Não se pode desvencilhar a língua e a sua materialização através dos gêneros do discurso, literários, retóricos... dos falantes e do mundo em que vivem. Para Bakhtin, a língua é produto e produtora das ideologias.

\section{II- DESENVOLVIMENTO}

Segundo Bakhtin, não podemos ignorar a natureza do enunciado, que assinala a variedade do discurso, devemos considerar a historicidade dele, o seu cronotopo, a fim de não enfraquecer o vínculo existente entre a língua e a vida. "A língua penetra na vida através dos enunciados concretos que a realizam, e é também através dos enunciados concretos que a vida penetra na língua”. (BAKHTIN, 1997: 282)

O enunciado da Carolina de Jesus em "Quarto de despejo: diário de uma favelada" é um enunciado secundário (complexo), um gênero literário (romance), composto de enunciados primários transformados, principalmente, diário íntimo.

Segundo Bakhtin, compreender a natureza do enunciado é indispensável para qualquer estudo. O enunciado é sempre individual, reflete a individualidade de quem fala, em outras palavras, possui “estilo individual”.

E o estilo individual da Carolina de Jesus é particularmente ímpar, por ser o discurso de uma favelada, negra e pouco escolarizada, porém de uma poética e consciência social enorme. "Mas o custo dos generos alimenticios nos impede a realização dos nossos desejos. Atualmente somos escravos do custo de vida." (JESUS, 20I4:II), exemplo de crítica social. No excerto seguinte, percebe-se a sua crítica à violência contra a mulher e a consciência de que os filhos não deveriam presenciar esses maus exemplos.

\footnotetext{
"A Silvia e o esposo já iniciaram o espetaculo ao ar livre. Ele está lhe espancando. E eu estou revoltada com o que as crianças presenciam. Ouvem palavras de baixo calão. Oh! se eu pudesse mudar daqui para um nucleo mais decente"(JESUS, 2014:14).

"E elas, tem que mendigar e ainda apanhar. Parece tambor. A noite enquanto elas pede socorro eu tranquilamente no meu barracão ouço valsas vienenses. Enquanto os esposos quebra as tabuas do barracão eu e meus filhos dormimos
} 
socegados. Não invejo as mulheres casadas da favela que levam vida de escravas indianas"(JESUS, 2004: 16,17)

A denúncia ao racismo, também está presente nesta obra: "Quando eu passava perto do campo do São Paulo, varias pessoas saiam do campo. Todas brancas, só um preto. E o preto começou insultar-me:" (JESUS, 2004: 14)

Podemos identificar o estilo individual da autora, dentre outros aspectos, no uso de figuras de linguagem, como a comparação em "Tenho pavor destas mulheres da favela. Tudo quer saber! A lingua delas é como os pés de galinha. Tudo espalha” (JESUS, 2014:I4 grifo nosso). Ou ainda na metáfora em: “... Elas vai na feira, cata cabeça de peixe, tudo que pode aproveitar. Come qualquer coisa. Tem estomago de cimento armado (...)" (JESUS, 2004: I9 grifo nosso). Notamos ainda, na manifestação de sua individualidade, sua visão de mundo, nesse elemento estilístico presente em sua obra.

Dentro da sua esfera cultural, ocorre claramente o que Bakhtin explica de que todo enunciado dialoga com outros enunciados "as obras dos antecessores, nas quais o autor se apóia, as obras de igual tendência, as obras de tendência oposta, com as quais o autor luta, etc" (BAKHTIN, 1997: 298)

A própria Carolina escreve em seu diário:

O nervoso interior que eu sentia ausentou-se. Aproveitei a minha calma interior para eu ler. Peguei uma revista e sentei no capim, recebendo os raios solar para aquecer-me. Li um conto. Quando iniciei outro surgiu os filhos pedindo pão. (JESUS, 2004: 12)

No enunciado da Carolina de Jesus temos a destruição e renovação do próprio gênero literário, romance, à medida em que ela trouxe a literatura popular, a dialogização, através do falado-dialogado, trazendo uma nova sensibilidade ao ouvinte, o Outro, leitor, que tem uma atitude responsiva ao ir ao encontro do enunciado dela.

E falamos de politicos. Quando uma senhora perguntou-me o que acho do Carlos Lacerda, respondi concientemente: - Muito inteligente. Mas não tem iducação. É um politico de cortiço. Que gosta de intriga. Um agitador. (JESUS, 2004: 15)

Durante todo o romance da Carolina, é possível perceber o diálogo com o Outro. A obra visa a uma resposta do Outro (s) quer uma compreensão responsiva ativa, porque apesar de ela escrever um diário que é um gênero discursivo que a princípio não 
pressupõe um leitor, ela tem um intuito discursivo, tem um querer-dizer que a impulsiona a escrever, mesmo que seja para si mesma.

Refleti: preciso ser tolerante com os meus filhos. Eles não tem ninguem no mundo a não ser eu. Como é pungente a condição de mulher sozinha sem um homem no lar. (JESUS, 2004: 22)

O estilo individual da autora, define-se, também, por sua expressividade e escolha de palavras. A palavra escolhida sempre expressa o juízo de valor do homem individual cuja época, meio social e micromundo dão o tom.

Mesmo elas aborrecendo-me, eu escrevo. Sei dominar meus impulsos. Tenho apenas dois anos de grupo escolar, mas procurei formar o meu carater. A unica coisa que não existe na favela é solidariedade. (JESUS, 2004: 16)

Ao escolher a palavra única para adjetivar o substantivo coisa que se refere à solidariedade, percebemos a valoração expressa pela autora dada ao seu meio social, e nós, o (s) Outro (s) que lemos o seu texto, numa posição responsiva pressupomos que tudo o mais de bom e ruim de valores existem na favela. Conforme afirma Bakhtin "A obra predetermina as posições responsivas do outro nas complexas condições da comunicação verbal de uma dada esfera cultural”. (BAKHTIN, 1997: 299)

Bakhtin afirma ainda que a expressividade é uma resposta em maior ou menor grau, a manifestação de uma relação do autor com o objeto enunciado, do locutor com os enunciados do Outro com os quais dialoga. Sendo assim, a Carolina ao escrever sobre a falta de solidariedade na favela, está respondendo a (s) fala (s) de outro (s), expressando sua opinião, que em outros momentos do livro ela retoma: "O desgosto que tenho é residir em favela." (JESUS, 2004: 22); "O que eu reprovo nas favelas são os pais que mandam os filhos comprar pinga e dá as crianças para beber" (JESUS, 2004: 2I); "Estou residindo na favela. Mas se Deus me ajudar hei de mudar daqui". ( JESUS, 2004: 20)

Como explicitou Bakhtin, o enunciado é complexo e polimorfo, desde que o analisemos dialogicamente em sua "relação com o autor (o locutor) e enquanto elo na cadeia da comunicação verbal, em sua relação com os outros enunciados (uma relação que não se costuma procurar no plano verbal, estilístico composicional, mas no plano do objeto do sentido)". (BAKHTIN, I997: 318,319) 
O que estamos querendo dizer é que o enunciado nunca é neutro, ele é composto por pelo menos três vozes: a do locutor, a do Outro com o qual ele dialoga direta ou indiretamente e a do leitor, que por sua vez também dialoga com Outro (s). O enunciado é um elo na cadeia da comunicação verbal, determinado pela alternância dos sujeitos.

Sendo assim, a compreensão da obra modifica-se completamente de leitor para leitor porque cada um é único, com visões de mundo particulares.

A concepção de alteridade, de que o discurso do locutor sempre está voltado, relacionado a discursos anteriores e futuros. Assim, expõe Bakhtin "o enunciado está ligado não só aos elos que o precedem mas também aos que lhe sucedem na cadeia da comunicação verbal”. (BAKHTIN,I997 : 321) O que pode ser muito bem percebido no seguinte trecho:

... Estive revendo os aborrecimentos que tive esses dias (...) Suporto as contingências da vida resoluta. Eu não consegui armazenar para viver, resolvi armazenar paciência. Nunca feri ninguem. Tenho muito senso! Não quero ter processos. O meu risgistro geral é 845.936. (JESUS, 2004: 18)

No trecho, o Outro com quem a Carolina dialoga, a princípio, é ela mesma. Percebemos pelo uso do tempo verbal no pretérito imperfeito do indicativo "estive revendo" e dos pretéritos perfeitos em "tive", "consegui armazenar", "resolvi armazenar" e "feri". O enunciado liga-se ao discurso no presente "suporto", "tenho", “é” e ao futuro com o uso da locução verbal "quero ter". Esse uso é comum na linguagem coloquial da nossa língua, equivalente ao futuro do presente.

\section{CONCLUSÃO}

"A língua penetra na vida através dos enunciados concretos que a realizam, e é também através dos enunciados concretos que a vida penetra na língua." (BAKHTIN, 1997: 282)

Esse livro de literatura marginal brasileira foi traduzido em is idiomas e publicado em mais de 40 países, entretanto, ainda encontra-se desconhecido de grande parte dos leitores brasileiros, apesar do enorme sucesso de vendas e de reconhecimento internacional. Passados mais de 60 anos de sua primeira publicação, a obra ainda é contemporânea pois seu conteúdo permanece atual: pobreza, racismo, violência contra a 
mulher e fome. Estes assuntos já tornam sua leitura crucial, para além deles, o livro traz o enunciado discursivo, de acordo com o conceito bakhtiniano, de uma mulher excluída socialmente, dá-lhe empoderamento e sua palavra torna-se a ponte entre ela e o Outro (s), possibilitando que este(s) Outro (s) também inserido (s) em um contexto social, cultural e ideológico possa agir para transformar essa sociedade.

A linguagem dessa obra de Carolina é peculiar visto que é híbrida, recorre a elementos da língua e literatura canônica utilizando-se em parte, de suas formas e gêneros discursivos, o diário pessoal e o romance e simultaneamente, faz migrar formas de expressão e de vida populares e de favelados para o interior de suas narrativas. Por vivência e experiências próprias, seu enunciado discursivo literário tem uma significância verdadeira e afastado de uma linguagem maniqueísta, pois a realidade do sujeito Carolina insere-se contextualizada histórica, cultural e ideologicamente na favela de Canindé. Esta hibridização dos gêneros discursivos, observáveis nessa obra analisada é devido às características composicionais, e estilísticas e temáticas dos gêneros discursivos que somente são observáveis pelo diálogo entre autor e interlocutor, requerendo sempre uma compreensão ativa e responsiva do leitor.

A teoria bakhtiniana de análise dialógica do discurso é possível de ser utilizada ainda hoje, conforme verificamos, não somente para análise de gêneros discursivos tradicionais como esse romance "Quarto de despejo: diário de uma favelada", mas também para análise dos novos gêneros discursivos, criados a partir das TICs, porque ele considerou o sujeito, o outro, as esferas de comunicação e os contextos histórico, social, cultural e ideológico no uso efetivo da linguagem. Dessa forma, sua teoria tornase atemporal.

Enfim, esperamos ter demonstrado o vínculo entre a língua e vida, através da interpretação de trechos desse clássico da nossa literatura à luz de alguns conceitos da teoria bakhtiniana: dialogismo, o Outro (alternância dos sujeitos falantes), atitude responsiva e esferas da comunicação. Assim, concluímos com Bakhtin "As palavras dos outros introduzem sua própria expressividade, seu tom valorativo, que assimilamos, reestruturamos, modificamos". (BAKHTIN, 1997: 314) 


\section{REFERÊNCIAS BIBLIOGRÁFICAS}

BAKHTIN, Mikhail. "Os gêneros do discurso". In: Estética da criação verbal. São Paulo: Martins Fontes, 1997. 2 ed.

BRAIT, BETH. Bakhtin - Conceitos-Chave, Ed. Contexto, 2005. 3. Bakhtin dialogismo e polifonia. São Paulo: Contexto, 2009.

4. FANIN, Angela Maria Rubel. "A centralidade da linguagem e do trabalho em Quarto de Despejo". Revista Línguas \& Letras - Unioeste - Vol. 15 - № 29 - Segundo Semestre de 2014 e-ISSN: I98I-4755 Disponível em : https://erevista.unioeste.br/index.php/linguaseletras/article/download/9753/8013/40073 Acesso em: 02 jan.2022

5- JESUS, Carolina Maria de. Quarto de despejo: diário de uma favelada. São Paulo: Ática, 2014. roed.

6. VOLOSHINOV. V. "A interação verbal". In: . /BAKHTIN, M. Marxismo e Filosofia da Linguagem. São Paulo, Hucitec, 1969. Orig.1929. 